\title{
Effects of verb complexity on speech errors
}

\author{
Kathleen T. Ashenfelter and Kathleen M. Eberhard \\ University of Notre Dame, Notre Dame, Indiana
}

\begin{abstract}
Two experiments examined whether semantically related verbs that contrast with respect to the absence versus the presence of an additional semantic feature differentially compete for selection during the encoding of a sentence for production. In both experiments, a speech error induction task was used to elicit contextual (misordering) errors involving semantically related verbs that contrasted only in their semantic complexity or in both their semantic and morphophonological complexity. The prediction was that an asymmetry in contextual errors would be observed in which the more complex verbs would replace the simpler verbs more often than the reverse. This prediction was confirmed in both experiments, with more perseverations and anticipations involving the semantically more complex verb of antonym pairs in Experiment 1, and more perseverations and anticipations involving the semantically more-specified verb of a heavy-light pair in Experiment 2. The implications of the results for spreading-activation theories of language production are discussed.
\end{abstract}

Language is a discrete combinatorial system in which simpler representations combine to form more complex representations. One consequence of this system, which is examined by the research reported below, is that two distinct linguistic representations at a particular level may overlap in the components that form them, contrasting only with respect to one representation possessing an additional component in comparison with the other. This contrast is evident in verb paradigms in which morphophonological forms are derived from a base form by the addition of an inflection as well as one or more unbound morphemesfor example, zip versus am zipping. In addition, verbs - as well as words of other grammatical categories - may contrast with respect to the addition of a derivational affix to the base form - for example, zip versus unzip. In both cases, the asymmetry in the compositional complexity of the morphophonological forms reflects a corresponding asymmetry in the compositional complexity of their semantic representations. For example, the semantic contrast between zip and am zipping may be characterized as the absence versus the presence of an aspectual feature specifying an event of limited duration (see, e.g., Clark \& Stafford, 1969; Comrie, 1998; Quirk, Greenbaum, Leech, \& Svartvik, 1985). The semantic contrast between the antonyms zip and unzip may be characterized as the absence versus the presence of a negation feature specifying a reversal of the action (e.g., Quirk et al., 1985).

However, not all asymmetries in semantic complexity are reflected in a corresponding asymmetry in morphophonological complexity. For example, like the semantic contrast between zip and unzip, the contrast between inflate and deflate may be characterized as the absence versus the presence of a negation feature that specifies a reversal of the action. Furthermore, many theories of lexical semantics assume that the semantic representations of all verbs are derived from a core set of primitive concepts that combine with conceptual features and functions or operators that map between values of the features (see, e.g., Bierwisch \& Schreuder, 1992; Jackendoff, 1990, 1991; G. A. Miller \& Johnson-Laird, 1976; Pinker, 1989). Consequently, the semantic contrast between verbs such as cut and chop may be characterized as the absence versus the presence of a feature specifying the manner of the action, which is not reflected in a corresponding contrast in the complexity of the verbs' morphophonological forms.

The goal of the present experiments was to investigate the effects of asymmetries in the compositional complexity of the morphophonological and/or semantic representations of verbs on their encoding during language production. The basic predictions stem from the fundamental assumption of most theories of production that the processes of encoding an utterance are competitive. Specifically, most theories assume that the encoding proceeds through two general stages: grammatical encoding and morphophonological encoding (see, e.g., Bock, 1982, 1995; Bock \& Levelt, 1994; Dell, 1986; Dell, Schwartz, Martin, Saffran, \& Gagnon, 1997; Garrett, 1988; Levelt, 1989; Levelt, Roelofs, \& Meyer, 1999; Stemberger, 1985). Grammatical encoding begins when the semantic representations of a to-be-communicated message spread activation across associative links to abstract word representations, referred to as lemmas. Lemmas contain information about words' grammatical properties, such as their grammatical category (Butterworth, 1989; Fromkin, 1973; Garrett, 1980, 1982, 1988). Lemmas compete via their activation levels for assignment to positions in a syntactic plan for the utterance. In all computational models of language production that instantiate the pro-

K. M. Eberhard, eberhard.1@nd.edu 
cess of spreading activation, a primary factor - albeit not the only factor - that affects a lemma's activation level is the number of other representations (or processing units) that spread positive activation to it (e.g., Dell, 1986; Dell, Burger, \& Svec, 1997; Dell, Schwartz, et al., 1997; Gordon \& Dell, 2003; Levelt, Roelofs, \& Meyer, 1999; Roelofs, 1992, 1993, 1997; Schade \& Berg, 1992; Starreveld \& La Heij, 1999; Stemberger, 1985). ${ }^{1}$ The competition for assignment to positions in the syntactic plan is resolved in favor of the most highly activated lemmas, which are the ones that best match the conceptual representations of the to-be-communicated message. Consequently, lemmas with overlapping conceptual or semantic representations should differentially compete with each other. This consequence is a general convergence problem, known as the hypernym problem, which challenges theories that assume decompositional semantic representations (e.g., Bierwisch \& Schreuder, 1992; Fodor, Garrett, Walker, \& Parkes, 1980; Levelt, 1989; Levelt et al., 1999; Roelofs, 1992, 1993, 1997). However, as we will argue, the tendency for componentially simpler representations to be greater in frequency may provide a solution to this problem.

\section{Hypernym Problem}

According to Levelt (1989), a word, such as cut, is a hypernym of another word, such as chop, because the meaning of chop entails the meaning of cut, but not vice versa. The verb chop, in turn, is a hyponym of the verb cut. Given this entailment relation, the problem concerns how the activated set of semantic features converge on the lemma for chop rather than on the lemma for cut, or vice versa.

The WEAVER ++ model of language production developed by Roelofs (1992, 1993, 1997; Levelt et al., 1999) solves the convergence problem by assuming that the conceptual representation of the to-be-communicated message consists of unitary concepts that have one-to-one associative connections with lemmas. Complex concepts, such as the one associated with the lemma chop, are chunks that decompose into (via associative connections with) their constituent concepts. However, the direct connection between a unitary concept and a lemma ensures that when the concept is part of the to-be-encoded message, the corresponding lemma will be the most highly activated.

Nevertheless, it may be possible for spreading activation models to maintain the assumption of decomposed semantic representations, given that - as stated previously-the activation levels of lemmas are determined in large part by the number of representations spreading positive activation to them. For example, in the case of input that includes the semantic features that are common to both chop and cut as well as the additional manner feature distinguishing chop, the additional feature will increase the activation level of chop's lemma above the activation level of cut's lemma, thereby resolving the competition in favor of the hyponym.

However, when the semantic input does not contain the additional manner feature, the same number of semantic features will spread activation to both the lemmas for $\mathrm{cut}$ and chop, causing them to be equally activated. The reso- lution of the competition in favor of the hypernym may result from a second important factor that is assumed to affect activation levels - namely, frequency of occurrence. In particular, semantically simpler verbs, particularly light verbs (Jesperson, 1965) that correspond to primitive concepts (e.g., go, come, take), have a higher frequency of occurrence than do semantically complex or heavy verbs-for example, fly, drive, grab (see, e.g., Breedin, Saffran, \& Schwartz, 1998). This is true in the example above, where the log frequencies of cut and chop from the CELEX lemma frequency database (Baayen et al., 1995) are 3.53 and 2.54 , respectively.

\section{A Solution to the Hypernym Problem}

Evidence of facilitative effects of frequency in language production comes from Oldfield and Wingfield's (1965; Wingfield, 1967, 1968) findings that naming times for pictures of objects decrease as the log frequency of the objects' names increases. In addition, Stemberger and MacWhinney (1986) found that speech errors involving the loss of inflections on verbs occurred less often with high-frequency verbs (e.g., waited $\rightarrow$ wait $)^{2}$ than with lowfrequency verbs (weeded $\rightarrow$ weed). Similarly, Dell (1990) found that high-frequency words are less prone to speech errors involving their phonological segments. A series of experiments by Jescheniak and Levelt (1994) localized the effects of frequency to the stage of encoding the morphophonological representations of words. In particular, in one experiment, they found that low-frequency words (e.g., moor) that are homophonous with a high-frequency word (more) are named as fast as high-frequency nonhomophonic words (e.g., much) and faster than matching low-frequency nonhomophonic words (marsh).

Jescheniak and Levelt's (1994) results imply that if frequency plays a role in solving the hypernym problem, then it does so by increasing the activation level-or accessibility - of the hypernym's morphophonological representation. This solution is viable, given evidence for a cascaded spreading activation process in which activation is spread from lemmas to associated morphophonological representations before the competition among semantically related lemmas is resolved (see, e.g., Costa, Caramazza, \& Sebastián-Gallés, 2000; Cutting \& Ferreira, 1999; Dell \& O’Seaghdha, 1992; Griffin \& Bock, 1998; Harley, 1993; Jescheniak \& Schriefers, 1998; Martin, Weisberg, \& Saffran, 1989; Peterson \& Savoy, 1998). Furthermore, although evidence that activation feeds back from morphophonological representations to their lemmas is controversial (e.g., Bock, 1986; Dell, 1985, 1986; Dell \& Reich, 1981; Hartsuiker, Corley, \& Martensen, 2005; Levelt et al., 1999; Rapp \& Goldrick, 2000, 2004; Roelofs, 2004; Stemberger, 1985), it would allow the greater activation of the more frequent hypernym's morphophonological representation to directly contribute to the activation level of the hypernym's lemma, thereby resolving its competition with a hyponym.

Evidence that frequency plays a role in resolving the hypernym problem comes from a series of model simulations by Gordon and Dell (2002, 2003). Their model simulated only the processes involved in encoding lemma 
representations, and not the subsequent processes of morphophonological encoding. Thus, the locus of the frequency effects in their simulations was the strength of the connections between lemmas and grammatical category features (e.g., determiner, noun, verb), which are assumed to be important for the process of assigning lemmas to slots in the syntactic plan. Gordon and Dell's simulations showed that when the input to lemma encoding was a set of activated semantic features associated with a semantically light verb (e.g., go), which was a subset of the features associated with a semantically heavy verb (e.g., fly), the light verb's lemma nonetheless achieved an activation level that was more than twice that of the heavy verb's lemma. This outcome was due in large part to the more frequent light verb, having a stronger connection (higher weight value) with the grammatical feature for verb, and stronger connections transmit a greater proportion of activation. Thus, in the absence of an activated semantic feature that favored the heavy verb over the light verb, the stronger connection with the verb feature allowed the competition between the two verbs' lemmas to be resolved in favor of the more frequent one. When the set of activated semantic features included the added feature that distinguished the heavy verb from the light verb, the heavy verb's lemma achieved an activation level that was twice that of the light verb's lemma.

The countereffects of semantic complexity and frequency in the model were further supported by simulations in which the model was lesioned to simulate agrammatic aphasia by reducing the strength of the connections between lemmas and grammatical category features. Specifically, when the strength of the connections was reduced by $75 \%$ or more, the model's accuracy of producing simple sentences with heavy verbs was greater than its accuracy of producing simple sentences with the more frequent light verbs, which is consistent with the results of several production studies involving agrammatic patients (Breedin, Boronat, Saffran, \& Shipley, 1999; Breedin et al., 1998; Marshall, Pring, Chiat, \& Robson, 2001). The model's output showed a reverse effect when it was lesioned to simulate anomic aphasia by reducing the strength of the connections between semantic features and the lemmas. Specifically, consistent with anomics' tendency to produce proportionately more light verbs than heavy verbs (e.g., Berndt, Haendiges, Mitchum, \& Sandson, 1997; Kohn, Lorch, \& Pearson, 1989), the model's output was significantly more likely to contain a light verb than a heavy verb, even when the semantic features in the input corresponded to the heavy verb.

On the basis of their simulation results, Gordon and Dell $(2002,2003)$ proposed that the distinction between content words (e.g., nouns, verbs, adjectives, adverbs) and function words (e.g., prepositions, determiners, auxiliary verbs, as well as derivational morphemes) can be characterized as two ends of a continuum. As the two terms imply, content words have more semantic content (richer meaning), whereas the more frequent and phonologically simpler function words perform important grammatical functions in an utterance. Light verbs represent a midpoint on this continuum.
The hypothesized countereffects of semantic complexity and frequency on the encoding of lemmas during production may be responsible for the failure to find a dominant effect of either factor in naturally occurring semantic substitution errors. In particular, there is no reliable tendency for the substituting word to be either semantically more complex (marked) than the intended word or semantically simpler but more frequent than the intended word (Garrett, 1992, 2001; Harley \& MacAndrew, 2001; Hotopf, 1980; Levelt, 1989). Even errors in which the substituting word is an antonym of the intended word, which predominate in substitutions involving adjectives and verbs (Garrett, 1992), do not exhibit a consistent asymmetry with respect to semantic complexity, morphophonological complexity, or frequency (see, e.g., Garrett, 1992, 2001). However, a frequency asymmetry was found in del Viso, Igoa, and García-Albea's (1991) analyses of a Spanish corpora of naturally occurring word substitution errors, but only for errors in which the substituting and intended words were phonologically related, which is consistent with Jescheniak and Levelt's (1994) findings that frequency affects the encoding of morphophonological representations.

\section{Antifrequency Effects in Contextual Errors}

The hypothesized countereffects of complexity and frequency also present a challenge to obtaining empirical evidence for them. However, Stemberger's $(1991,2004)$ findings of an antifrequency effect in contextual (misordering) errors involving phonetically related phonemes suggests a condition in which frequency may not counter the effects of complexity. Specifically, in both naturally occurring and experimentally elicited errors, lower frequency phonemes that possess a specified phonetic feature (e.g., / / $/$ ) replaced higher frequency phonemes that were unspecified for the particular feature (e.g., /s/) more often than the reverse. In contrast, noncontextual substitution errors exhibited a frequency effect, with higher frequency underspecified phonemes replacing lower frequency specified phonemes more often than the reverse.

Stemberger (1990, 1991, 1992; Stemberger \& Treiman, 1986) also reported an antifrequency effect in the form of an "addition bias" in phoneme contextual errors involving consonant clusters. Specifically, errors in which a consonant cluster was repeated because of the addition of a consonant to a singleton (e.g., round trip ticket $\rightarrow$ round trip tricket) occurred more often than errors in which a singleton was repeated because of the loss of a consonant from a cluster (e.g., round trip ticket $\rightarrow$ round tip ticket).

Stemberger (1991) attributed both forms of the antifrequency effect to the lower frequency phoneme or cluster possessing a highly activated constituent (feature specification or additional consonant) that receives no competition from a corresponding activated constituent in the higher frequency phoneme or singleton. When the lower frequency specified phoneme or cluster occurs in the same phrase as the higher frequency underspecified phoneme or singleton, the constituents of both will be highly activated in close temporal proximity. Thus, the asymmetrical competition between a specified phoneme and an unspecified phoneme or a cluster and a singleton will most likely be 
reflected in an asymmetry in contextual errors involving these units.

The following experiments examined whether the antifrequency effect in contextual errors involving phonemes would also be observed in contextual errors involving words that contrast in their semantic complexity. Specifically, the prediction was that under conditions in which two related verbs that contrast in their semantic complexity are to be encoded in the same utterance, the additional highly activated semantic features of the more complex verb should cause the more complex verb's lemma to be a stronger competitor to the semantically simpler, albeit more frequent, verb. This competition, in turn, should be reflected in an asymmetry in contextual errors such that the more complex verb replaces the simpler verb more often than the reverse.

Experiment 1 tested this prediction with pairs of verb antonyms in which the complex verb possessed a negation feature corresponding to either an "undoing" of the simpler verb's action or "not" doing the simpler verb's action. In addition, antonym pairs that had a corresponding contrast in their morphophonological complexity (e.g., zip-unzip, obey-disobey) were compared with antonym pairs that were symmetrical in their morphophonological complexity (e.g., inflate-deflate, include-exclude). This comparison allowed an assessment of the degree to which a contrast in the complexity of both the semantic and the morphophonological representations increases the asymmetry in contextual errors. Specifically, there is ample evidence for a point in production when morphologically complex words (derived or inflected) are assembled from their components (Dell, 1986; Ferreira \& Humphreys, 2001; Garrett, 1980, 1988; Janssen, Roelofs, \& Levelt, 2002, 2004; Melinger, 2003; Pillon, 1998; Roeloffs, 1996; Roelofs \& Baayen, 2002; Stemberger, 1985). Furthermore, analyses of experimentally elicited speech errors as well as production latencies for morphologically complex words have shown that this assembly process occurs for both semantically transparent and opaque words (see, e.g., Janssen et al., 2004; Melinger, 2003; Pillon, 1998; Roeloffs \& Baayen, 2002).

Experiment 2 tested the predicted asymmetry in errors with pairs of semantically related light and heavy verbs, such as cut and chop, which contrasted with respect to the absence versus the presence of one or more specified conceptual features. This experiment also examined the effects of a contrast in morphophonological complexity by comparing the asymmetry in contextual errors when the tense and aspect features were the same for both the light and the heavy verbs with the asymmetry when the heavy verb possessed an additional feature for progressive aspect, which is morphophonologically realized by the addition of an auxiliary verb plus the -ing inflection (i.e., cuts vs. is chopping).

In both experiments, the primary dependent measure is the number of contextual errors (anticipations and perseverations) reflecting the erroneous replacement of the simpler verb with the more complex verb versus the erroneous replacement of the complex verb with the simpler verb. Errors were elicited using the ordinal conflict technique developed by Baars (1992; Baars \& MacKay,
1978). Specifically, on each trial, a sentence with two conjoined verb phrases was displayed in the center of a computer screen. The sentence remained on the screen until the participants pressed a key indicating that they could reproduce the sentence from memory. The sentence was then replaced by either SAME or REVERSE, which cued the participants to produce the sentence with the verb phrases either in the same order as they were presented or in reverse. Table 1 shows an example of sequences of sentences and cues that were presented in Experiment 1. All of the critical sentences were cued with REVERSE, and each was preceded by two to six filler sentences that were cued with SAME, with the number of preceding fillers being unpredictable. Thus, the repeated occurrence of the SAME cue primed an ordering of the verb phrases that conflicted with the order required by the REVERSE cue, thereby increasing the likelihood of a misordering error in the responses to the critical sentences.

\section{EXPERIMENT 1}

The critical stimuli presented in the first experiment consisted of verb antonyms that differed in both their semantic and morphophonological complexity, as well as verb antonyms that differed only with respect to their semantic complexity. Examples of critical sentences representing the two complexity conditions are given in Table 2. Both conditions of verb pairs were expected to exhibit an asymmetry in contextual errors, with the semantically more complex verb replacing the simpler verb more often than the reverse. In particular, the additional semantic feature of the more complex verb was expected to increase its lemma's activation level, thereby increasing its competition for assignment to the syntactic plan for the utterance. Furthermore, the size of the asymmetry might be greater for antonym pairs in the semantic plus morphophonological condition due to the contrast in com-

Table 1

Example Sequences of Sentences and Cues for Eliciting a Movement Error Involving the Verbs

He rents the car and sells the van. SAME

We advise the senator and devise the plot. SAME

They come to the mall and flock to the store. SAME

She [unties the knot] and [ties the shoes]. REVERSE

They sit on the couch and bounce on the bed. SAME

He pays the fine and repays his debt. SAME

They recite the lesson and repeat the words. SAME

Peg combs her bangs and brushes her teeth. SAME

They [progress with the cure] and [regress with the cause]. REVERSE

Note-The phrases to be produced in reverse order are indicated in brackets. 
Table 2

Examples of Sentences Representing the Two Complexity Conditions in Experiment 1

\begin{tabular}{ll}
\hline \multicolumn{1}{c}{ Semantic } & Semantic Plus Morphophonological \\
\hline $\begin{array}{l}\text { He discourages his wife and } \\
\text { encourages his son. }\end{array}$ & $\begin{array}{l}\text { She } \text { unties the knot and ties the } \\
\text { shoe. }\end{array}$ \\
$\begin{array}{l}\text { She enables the virus and dis- } \\
\text { ables the code. }\end{array}$ & $\begin{array}{l}\text { He likes the woods and dislikes the } \\
\text { beach. }\end{array}$ \\
\hline
\end{tabular}

Note-The more complex verb is indicated by italics.

positional complexity at the level of both semantic and morphophonological representations, further increasing the complex verb's competitiveness.

\section{Method}

Participants. Forty-eight individuals participated in this experiment. They were students from the University of Notre Dame or adults from the local community. The students received credit in their psychology courses in exchange for their participation. All were native English speakers who had normal or corrected-tonormal vision.

Materials. The materials consisted of 40 pairs of semantically related simple and complex verbs that were antonyms. The pairs were selected from the online WordNet database (G. Miller, Beckwith, Fellbaum, Gross, \& Miller, 1990), which provides a detailed classification of words on the basis of their semantic relations. The entries in the database provide a listing of all of a verb's core meanings or senses, which are ordered by frequency. Each sense also lists verbs that express the opposite sense. Thus, pairs of verb antonyms were selected so that for both verbs in a pair, the first or second most frequent sense named the other verb as opposite.

Twenty pairs represented the semantic plus morphophonological condition. In each pair, the complex verb consisted of the simple verb's stem plus either the prefix un- (10 pairs) or the prefix dis(10 pairs). In 7 pairs, the complex verb's additional semantic feature negated the simple verb's action or state (e.g., obey-disobey, like-dislike). In the other 13 pairs, the complex verb's additional semantic feature reversed the simple verb's action with privative force-for example, zip-unzip, tie-untie, assemble-disassemble, and arm-disarm.

Each of the 20 verb pairs in the semantic-only condition consisted of two verbs with the same base morpheme bound to different prefixes. ${ }^{3}$ In three pairs, the complex verb's added semantic feature negated the simple verb's action - for example, assent-dissent, include-exclude, and encourage-discourage. In the other 17 pairs, the complex verb's added semantic feature reversed the simple verb's action with privative force-for example, inhale-exhale, enabledisable, and inflate-deflate.

The frequency of occurrence of both the simple and the complex verbs in all 40 pairs was obtained from the CELEX lemma frequency database (Baayen, Piepenbrock, \& Gulikers, 1995). In the semantic plus morphophonological condition, the simple verb's frequency was dominant in all 20 verb pairs. The average log frequency of all 20 simple verbs was 2.73 (range, 1.64-3.77), and the average $\log$ frequency of the 20 complex verbs was 1.51 (range, 0.50-3.09). The simple verb's frequency was dominant in 17 of the 20 verb pairs in the semantic-only condition. The simple verbs' average log frequency was 2.28 (range, 0.85-3.62), and the complex verbs' average $\log$ frequency was 1.50 (range, $0.50-2.62$ ). The results of a $2 \times 2$ mixed ANOVA showed that the overall log frequency of the verbs in the two conditions was the same $[F(1,38)<1]$. In addition, the simple verbs' average log frequency was significantly higher than that of the complex verbs $[F(1,38)=73.12, p<.0001]$. The difference between the simple and complex verbs' log frequencies was marginally larger in the semantic plus morphophonological condition $[F(1,38)=3.46, p=.07]$.
Four versions of sentences were constructed for each of the 40 verb pairs. Each sentence consisted of a subject pronoun (he, she, it, we, or they) followed by two conjoined verb phrases, both with definite noun-phrase complements or both with prepositional-phrase complements. The two complements had the same number of words and were sensible with each verb as the head. The four versions of sentences were created by crossing the order of the complex and simple verbs with the order of the complement phrases that followed them. The set of critical sentences and the log frequencies of their simple and complex verbs is given in Appendix A.

In addition to the critical sentences, the materials included 180 filler sentences. Like the critical sentences, all of the filler sentences had a subject noun followed by two conjoined verb phrases. To add variety, $37 \%$ of the fillers began with a subject noun that was a monosyllabic common name (e.g., Bill, Sam, Barb, Ann), whereas the other $63 \%$ began with a subject pronoun (he, she, it, we, or they). The two verbs in $54 \%$ of the fillers were neither semantically nor morphophonologically related. The two verbs in the other $46 \%$ of the fillers resembled the relations between the pairs of verbs in the critical sentences. Specifically, 39 fillers had two verbs that were semantically related but morphophonologically unrelated (e.g., swim-wade, comb-brush), with the relation being antonymic in approximately one third of these fillers, (e.g., marry-divorce, passfail). Thirteen fillers had semantically related verbs that contrasted with respect to the addition of the prefix re-, pre-, or mis-- for example, start-restart, order-preorder, remember-misremember. The remaining 31 fillers possessed semantically unrelated verbs that overlapped in their final syllable(s) - for example, observe-reserve, design-resign, collect-recollect.

Four lists were constructed, each containing all 180 filler sentences in random order and 40 critical sentences. One version of each critical sentence appeared in each list, and across all four lists, each version occurred once. Within a list, 20 critical sentences represented each complexity condition, with the simple verb occurring first in one half and the complex verb occurring first in the other half. The order of the critical sentences was randomly determined, except for the constraint that an equal number representing each condition occurred in each half of the list. In addition, each critical sentence was preceded by two to six fillers, with the number of preceding fillers being randomly determined.

Procedure. The participants were tested individually. They were seated in front of a computer and a microphone that was connected to a tape recorder. They were told that on each trial, a sentence with two conjoined verb phrases would appear in the center of the computer screen until they pressed the spacebar on the keyboard, at which point the sentence would be replaced by either the cue word SAME or REVERSE, indicating how they were to produce the sentence. They were instructed to produce the sentence aloud with the verb phrases in the same order as they had appeared in response to the SAME cue, and to produce the sentence with the entire verb phrases in reverse order in response to the REVERSE cue. An example sentence was used to illustrate the responses that were to be given to each cue. The participants were told that a beep would be sounded within $1 \mathrm{sec}$ after the cue word was displayed and would indicate the deadline by which they were to have begun producing their response.

Six practice trials preceded the 220 experimental trials in order to familiarize the participants with the procedure. An equal number of practice trials was followed by each cue word. During the practice trials, the experimenter corrected the participants if they failed to produce the sentence according to a cue. After the practice trials, the experimenter set the tape recorder to record and remained in the room while the participant completed the experimental trials. All of the filler sentences were followed by the SAME cue, and all of the critical sentences were followed by the REVERSE cue.

The presentation of the trials was controlled by PsyScope 1.2.5 (Cohen, MacWhinney, Flatt, \& Provost, 1993) running on an iMac with a 15 -in. CRT. The participant initiated each trial by pressing the spacebar on the keyboard. A sentence was displayed in 18-point font in the center of the screen and remained visible until the par- 
Table 3

Proportion of Responses in Each Condition That Were Assigned to Each Score Category in Experiment 1

\begin{tabular}{lcc}
\hline & \multicolumn{2}{c}{ Condition } \\
\cline { 2 - 3 } \multicolumn{1}{c}{ Score Category } & $\begin{array}{c}\text { Semantic Plus } \\
\text { Morphophonological }\end{array}$ & Semantic Only \\
\hline Correct Reversal & $.72(690)$ & $.66(632)$ \\
Error Categories & $.06(53)$ & $.03(26)$ \\
$\quad$ Complex verb & $.01(12)$ & $.01(13)$ \\
Simple verb & $.03(30)$ & $.04(34)$ \\
Complete exchange & $.18(171)$ & $.25(236)$ \\
Miscellaneous & $.004(4)$ & $.02(19)$ \\
No response &
\end{tabular}

Note-Actual numbers of responses are given in parentheses.

ticipant pressed the spacebar again. After a 150-msec delay, the cue word was displayed in capital letters in the center of the screen and remained there for a duration of $750 \mathrm{msec}$. The deadline beep was played over external speakers $150 \mathrm{msec}$ after the cue's offset. The screen remained blank until the participant completed his or her response and then pressed the spacebar to advance to the next trial.

Scoring. The responses on the critical trials were transcribed from the audio tapes and then assigned to one of six score categories. Examples of responses assigned to each score category are given in Appendix C. A response was scored as a "correct reversal" if the two complete verb phrases (verb plus complement) were produced in reverse order. Responses were scored as an "exchange" if the verb phrases' complements were produced in the correct reversal order but the simple and complex verbs were not. A response was scored as a "complex verb" error if the complex verb was the first verb or only verb produced as the head of both verb phrases. When the complex verb was the first verb produced in a verb phrase, it was followed by a self-correction with the simple verb, which occurred after either the complex verb's initial syllable or its entire form was produced. Conversely, a response was scored as a "simple verb" error if the simple verb was the first or only verb produced as the head of both verb phrases. When the simple verb was the first verb produced in a verb phrase, it was followed by a self-correction with the complex verb, which occurred after either the simple verb's initial syllable or its entire form was produced. Responses were scored as "no response" if no verb was produced. All other responses were scored as "miscellaneous" and included failures to reverse the verb phrases (i.e., the sentence was produced as it was displayed), responses in which the complex and simple verbs were reversed, but not their complement phrases (i.e., a complement exchange error), incomplete responses consisting of only one verb phrase, and responses in which there was an erroneous substitution or misrepetition of a verb or noun in the complement phrase.

\section{Results}

Table 3 shows the proportion of responses in each condition that occurred in each of the score categories. The responses that were scored as a complex verb error or a simple verb error were analyzed with two $2 \times 2$ ANOVAs, one with participants as a random factor and the other with items as a random factor, designated $F_{1}$ and $F_{2}$, respectively. The type of error (complex vs. simple) was a within-participants factor as well as a within-items factor, and the type of complexity (semantic only vs. semantic plus morphophonological) was a within-participants factor and a between-items factor.

The combined total of complex and simple verb errors was greater in the semantic plus morphophonological condition than in the semantic-only condition $\left[F_{1}(1,47)=6.77, p<\right.$ $\left..05 ; F_{2}(1,38)=5.07, p<.05\right]$. In addition, there were more complex verb errors than simple verb errors $\left[F_{1}(1,47)=\right.$ $\left.20.50, p<.0001 ; F_{2}(1,38)=26.26, p<.0001\right]$. Furthermore, the asymmetry favoring complex verb errors was significantly larger in the semantic plus morphophonological condition than in the semantic-only condition $\left[F_{1}(1,47)=\right.$ $\left.8.02, p<.01 ; F_{2}(1,38)=7.06, p<.02\right]$.

Table 4 shows the numbers of complex verb errors and simple verb errors in each condition that involved an anticipation or perseveration of either the entire verb (e.g., He disassembles the engine and disassembles the axle) or just the verb's initial syllable or prefix, which was followed by a correction (e.g., He un ... seals the form and unseals the file). In both conditions and for both types of verb errors, there were more anticipations than perseverations and more errors involving the movement of the entire verb than just the movement of the initial syllable or prefix. Furthermore, in both conditions, complex verb errors outnumbered simple verb errors in the comparisons involving both the type and size of the movement error.

As shown in Table 3, there were more correct reversal responses in the semantic plus morphophonological condition than in the semantic-only condition, with the difference being significant in the participant analysis (Wilcoxon $\operatorname{sign} z=-2.42, p<.02$ ), but not in the item analysis (Mann-Whitney $z=-1.20, p>.05$ ). The fewer number of correct reversal responses in the semantic-only condition was due to a greater number of "no responses" in this condition (Wilcoxon sign $z=-2.67, p<.01$; Mann-Whitney $z=-2.22, p<.05$ ), as well as a greater number of miscellaneous responses (Wilcoxon sign $z=$ $-2.77, p<.01$; Mann-Whitney $z=-1.92, p=.05$ ).

Although there were more miscellaneous responses in the semantic-only condition, the percentages of responses receiving this score for various reasons were similar in both conditions. Specifically, in both conditions, most of the miscellaneous responses involved a failure to reverse

Table 4

Breakdown of Complex Verb Errors and Simple Verb Errors in Each Condition in Experiment 1

\begin{tabular}{lcccccc}
\hline & \multicolumn{2}{c}{$\begin{array}{c}\text { Semantic Plus } \\
\text { Morphophonological }\end{array}$} & & \multicolumn{2}{c}{ Semantic Only } \\
\cline { 2 - 3 } \cline { 5 - 6 } & Complex & Simple & & Complex & Simple \\
Form-Size of Replacing Unit & Errors & Errors & & Errors & Errors \\
\hline Anticipatory-1st syllable/prefix & 15 & 5 & & 11 & 5 \\
Anticipatory-whole word & 20 & 7 & & 6 & 6 \\
Perseveratory-1st syllable/prefix & 5 & 0 & & 1 & 0 \\
Perseveratory-word whole & 13 & 0 & & 6 & 2 \\
\hline
\end{tabular}


either the verb phrases' complements or the verb phrases (i.e., $43 \%$ of the miscellaneous responses in the semantic plus morphophonological condition and $38 \%$ of the miscellaneous responses in the semantic-only condition). The percentage of miscellaneous responses involving an erroneous substitution of one of the verbs was $13 \%$ in the semantic plus morphophonological condition and $12 \%$ in the semantic-only condition. The percentage of miscellaneous responses that were incomplete (i.e., only one verb or verb phrase was produced) was $26 \%$ in both conditions. The percentage of miscellaneous responses containing an erroneous substitution of an object noun in a complement was slightly higher in the semantic-only condition than in the semantic plus morphophonological condition $(24 \%$ and $18 \%$, respectively). However, none of the latter responses met the criteria for either a complex verb error score or a simple verb error score when the reason for their miscellaneous score was ignored.

\section{Discussion}

Both the semantic plus morphophonological condition and the semantic-only condition exhibited the predicted asymmetry in contextual errors, with complex verbs replacing simple verbs more often than the reverse. Furthermore, the asymmetry was larger in the semantic plus morphophonological condition than in the semantic-only condition because of the occurrence of twice as many complex verb errors (53 vs. 26 , respectively). The greater incidence of complex verb errors in the semantic plus morphophonological condition appears to be due to competition at the lemma level, because the errors exhibit the characteristics that are attributed to this level of processing. For example, according to Garrett $(1988,2001)$, errors involving words of the same grammatical category and from different phrases (such as the exchange error, How many pies does it take to make an apple? [Garrett, 1988, p. 76]) arise during the encoding of lemmas, whereas errors involving words of a different grammatical category and within the same phrase (such as the exchange, They were turking talkish [Garrett, 1988, p. 76]) arise during morphophonological encoding. In the present experiment, this distinction is illustrated by Responses 1 and 2:

\section{They lock the door and unlock the gate. $\rightarrow$ They unlock the door and unlock the gate.}

\section{They lock the door and unlock the gate. $\rightarrow$ They lock the door and ungate the lock.}

Response 1 was scored as a complex verb error, whereas Response 2, which was the only one of its kind, was scored as miscellaneous.

The asymmetry in the errors in both conditions reflects an "antifrequency" effect, because the simple verbs' frequency of occurrence was dominant in all 20 verb pairs in the semantic plus morphophonological and in 17 of the 20 verb pairs in the semantic-only condition. Furthermore, there was a significant positive correlation between the relative dominance of the simple verb's frequency in the 40 verb pairs and the number of complex verb errors associated with each pair $(r=.34, p=.03)$. When the pairs representing the two conditions were considered separately, the correlation was significant only in the semantic plus morphophonological condition $(r=.45, p=.05)$.

\section{EXPERIMENT 2}

The second experiment compared semantically related verb pairs that also contrasted in just their semantic complexity or in both their semantic complexity and morphophonological complexity. However, this experiment examined semantically related verbs that contrasted with respect to the absence versus the presence of specified conceptual features, such as a manner feature (e.g., cut vs. chop). In addition, the semantic complexity was further increased by the addition of a feature for progressive aspect, which resulted in a contrast in the morphophonological complexity of the simple and complex verbs. Examples of sentences representing the two complexity conditions are shown in Table 5.

Evidence that the progressive aspect is an added or marked semantic feature in comparison with the simple nonprogressive aspect comes from a cued recall task by Clark and Stafford (1969; see also Lapointe \& Dell, 1989). In particular, Clark and Stafford had participants study sentences in which the verb represented one of eight markedness contrasts resulting from combinations of tense, perfective aspect, and progressive aspect-for example, watch (simple present/base form), watched (simple past), is watching (present progressive), was watching (past progressive), has watched (present perfect), had watched (past perfect), has been watching (present perfect progressive), and had been watching (past perfect progressive). The subject noun phrases of the sentences served as cues for recall. Analyses of the recall errors demonstrated systematic simplifications for the aspectual contrasts, with progressive forms erroneously recalled in nonprogressive form, presumably because of the loss of the added semantic feature for progressive aspect.

In the present experiment, both complexity conditions were expected to exhibit the predicted asymmetry in contextual errors, with the semantically more complex verbs replacing the simpler verbs more often than the reverse. Furthermore, the asymmetry was expected to be larger in the semantic plus morphophonological condition.

\section{Method}

Participants. Forty undergraduates from the University of Notre Dame participated in the experiment in exchange for course credit in psychology courses. Participation was restricted to native English

\section{Table 5}

Examples of the Sentences Representing the Two Complexity Conditions in Experiment 2

\begin{tabular}{ll}
\hline \multicolumn{1}{c}{ Semantic } & Semantic Plus Morphophonological \\
\hline $\begin{array}{l}\text { She jogs to the zoo and goes to } \\
\text { the park. }\end{array}$ & $\begin{array}{l}\text { She is jogging to the zoo and goes } \\
\text { to the park. }\end{array}$ \\
$\begin{array}{ll}\text { They touch the apple and poke } \\
\text { the orange. }\end{array}$ & $\begin{array}{l}\text { They touch the apple and are pok- } \\
\text { ing the orange. }\end{array}$ \\
\hline
\end{tabular}

Note-The complex verb is indicated in italics. 
speakers with normal or corrected-to-normal vision. None had participated in Experiment 1.

Materials. The experimental materials were constructed from 32 pairs of semantically related verbs. The simple verbs were identified as a semantically light verb, general verb, or core (conceptually primitive) verb by Breedin, Saffran, and Schwartz (1998), Pinker (1999), or Jackendoff (1990), respectively. Each simple verb was paired with a complex verb that was a hyponym, as identified by a unilateral entailment relation: The meaning of the complex verb entailed the meaning of the simple verb, but not the reverse. Consequently, in comparison with the simple verb, the meaning of the complex verb possessed one or more additional semantic components corresponding to manner (e.g., cut-chop, move-slide), a change in the patient argument's state (e.g., put-stack, cover-encase, break-smash), intention (tell-warn), and others. In each pair, the simple and complex verbs required the same number and type of complements. In addition, the two verbs had the same number of syllables but were otherwise phonologically dissimilar.

For each verb pair, eight versions of sentences were constructed, with the two verbs appearing as heads of conjoined verb phrases in each version. Each version began with the same pronominal subject noun and had the same verb-phrase complements that made sense with either verb. Four versions represented the semantic-only condition, and four versions represented the semantic plus morphophonological condition. The two sets differed with respect to whether both verbs appeared in their simple present-tense forms (semanticonly condition), or whether the simple verb appeared in its simple present-tense form and the complex verb possessed the additional marking of progressive aspect (semantic plus morphophonological condition). The four versions in each set were created by crossing the order of the simple and complex verbs with that of the complement phrases that followed them. A list of the critical sentences is given in Appendix B.

On the basis of the CELEX lemma frequency database (Baayen, Piepenbrock, \& Gulikers, 1995), the simple verb's log frequency was dominant in all 32 pairs. The simple verbs' average log frequency was 4.16 and was significantly higher than the complex verbs' average $\log$ frequency of 2.40 [paired $t(31)=14.51, p<.0001$, twotailed].

The materials also included 144 filler sentences. The fillers had the same structure as the critical sentences, consisting of a subject pronoun that was followed by two conjoined verb phrases. In half of the filler sentences, one verb appeared in its simple present-tense form, and the other appeared in its present-progressive form. In the other half of the filler sentences, both verbs appeared in their simple present-tense forms.

Eight lists were constructed, each containing all 144 filler sentences and 32 critical sentences. Within a list, 16 critical sentences represented the semantic-only condition, 8 of which had the simple verb first, and 16 critical sentences represented the semantic plus morphophonological condition, 8 of which also had the simple verb first. Across all eight lists, the eight versions of each critical sentence occurred once. The order of the 32 critical sentences within the lists was randomly determined except for the constraint that 8 sentences representing each complexity condition occurred in each half of the list. In addition, each critical sentence was preceded by two to six fillers, with the number being randomly determined.

Procedure. The procedure was the same as that in Experiment 1.

Scoring. The responses on critical trials were transcribed from the audio tapes and assigned to a score category. Examples of responses in each score category are given in Appendix C. A response was scored as a "correct reversal" if both of the entire verb phrases were produced in the reverse order. A response was scored as an "exchange" if the verb phrases' complements were produced in reverse order, but the verbs were not. A response was scored as a "complex verb" error if either the simple present tense or the progressive form of the complex verb was the first or only verb produced as the head of both conjoined verb phrases. Conversely, a response was scored as a "simple verb" error if either the simple present tense or the pro- gressive form of the simple verb was the first or only verb produced as the head of both conjoined verb phrases. Responses were scored as a miscellaneous response if there was a failure to reverse the conjoined verb phrases, an erroneous substitution for one or more of the words in the sentence, or an incomplete response consisting of just the subject pronoun and one verb. A response was scored as an "aspect marking" error if progressive aspect was added to or deleted from a verb, and the response otherwise met the criteria for either a correct reversal score or a miscellaneous score. The "no response" category included responses in which no verb was produced.

\section{Results}

Table 6 shows the proportion of all responses in each condition that were assigned to each score category. The complex verb errors and simple verb errors were analyzed with two $2 \times 2$ repeated measures ANOVAs, one with participants as a random factor, and the other with items as a random factor. In both analyses, the two factors were the type of error (complex verb vs. simple verb) and type of complexity (semantic only vs. semantic plus morphophonological).

There were more complex verb errors than simple verb errors $\left[F_{1}(1,39)=26.98, p<.0001 ; F_{2}(1,31)=33.90, p<\right.$ $.0001]$. In addition, the combined total of complex- and simple-verb errors was greater in the semantic plus morphophonological condition than in the semantic-only condition $\left[F_{1}(1,39)=7.46, p<.01 ; F_{2}(1,31)=5.60\right.$, $p<.05]$. However, the size of the asymmetry favoring complex verb errors was the same in both conditions, as reflected by a nonsignificant interaction between type of error and type of complexity $\left[F_{1}(1,39)=1.50, p>.05\right.$; $\left.F_{2}(1,31)=1.61, p>.05\right]$.

As shown by the breakdown of the complex verb errors and simple verb errors in Table 7 , in both conditions and for both types of errors, there were more anticipations than perseverations. The table also shows that in the semantic plus morphophonological condition, 14 of the 30 complex verb errors involved the anticipation or perseveration of just the complex verb's stem, without progressive aspect-for example, She feels the curtain and is stroking the carpet $\rightarrow$ She strokes the curtain and is stroking the carpet. Two of the seven simple verb errors involved the anticipation or perseveration of just the simple verb's stem-for example, He asks for respect and is begging for help $\rightarrow$ He asks for respect and is asking for help.

Table 6

Proportion of Responses in Each Complexity Condition That Were Assigned to Each Score Category in Experiment 2

\begin{tabular}{lcc}
\hline & \multicolumn{2}{c}{ Condition } \\
\cline { 2 - 3 } \multicolumn{1}{c}{ Score Category } & $\begin{array}{c}\text { Semantic Plus } \\
\text { Morphophonological }\end{array}$ & Semantic Only \\
\hline Correct Reversal & $.52(333)$ & $.68(435)$ \\
Error Categories & $.05(30)$ & $.03(18)$ \\
Complex verb & $.01(7)$ & $.003(2)$ \\
Simple verb & $.03(21)$ & $.04(23)$ \\
Complete exchange & $.20(127)$ & $.06(37)$ \\
Aspect marking & $.17(111)$ & $.18(117)$ \\
Miscellaneous & $.02(11)$ & $.01(8)$ \\
No response &
\end{tabular}

Note-Actual numbers of responses are given in parentheses. 
Table 7

Breakdown of Complex Verb Errors and Simple Verb Errors in

Each Condition in Experiment 2

\begin{tabular}{|c|c|c|c|c|}
\hline \multirow[b]{2}{*}{ Form-Size of Replacing Unit } & \multicolumn{2}{|c|}{$\begin{array}{c}\text { Semantic Plus } \\
\text { Morphophonological }\end{array}$} & \multicolumn{2}{|c|}{ Semantic Only } \\
\hline & $\begin{array}{l}\text { Complex } \\
\text { Errors }\end{array}$ & $\begin{array}{l}\text { Simple } \\
\text { Errors }\end{array}$ & $\begin{array}{c}\text { Complex } \\
\text { Errors }\end{array}$ & $\begin{array}{l}\text { Simple } \\
\text { Errors }\end{array}$ \\
\hline Anticipatory-stem & 11 & 1 & - & - \\
\hline Anticipatory-inflected form & 14 & 5 & 15 & 1 \\
\hline Perseveratory-stem & 3 & 1 & - & - \\
\hline Perseveratory-inflected form & 2 & 0 & 3 & 1 \\
\hline
\end{tabular}

There were more correct responses in the semanticonly condition than in the semantic plus morphophonological condition (Wilcoxon sign $z=-3.97, p<.01$ by participants; Wilcoxon Sign $z=-3.91, p<.01$ by items). This difference was due to the higher incidence of aspectmarking errors in the semantic plus morphophonological condition, which was the only other score category in which the numbers of responses differed significantly between the two conditions (Wilcoxon Sign $z=-4.24, p<$ .01 by participants; Wilcoxon Sign $z=-4.61, p<.01$ by items). Of the 127 aspect-marking errors in the semantic plus morphophonological condition, 68 (54\%) involved the deletion of progressive aspect from the complex verb, $39(31 \%)$ involved the addition of progressive aspect to the simple verb, and the remaining 20 (16\%) involved both the deletion of progressive aspect from the complex verb and the addition of progressive aspect to the simple verb. Of the 37 aspect-marking errors in the semantic-only condition, $24(65 \%)$ involved the addition of progressive aspect to the complex verb, $10(27 \%)$ involved the addition of progressive aspect to the simple verb, and $3(8 \%)$ involved the addition of progressive aspect to both verbs.

The percentages of responses scored as miscellaneous for various reasons were approximately the same in both conditions. Specifically, most of the miscellaneous scores were due to a failure to reverse either the complements or the entire verb phrases $(38 \%$ of miscellaneous responses in the semantic plus morphophonological condition and $37 \%$ of miscellaneous responses in the semantic-only condition). The percentage of miscellaneous responses that were due to an erroneous substitution of a verb was $32 \%$ in the semantic plus morphophonological condition and $34 \%$ in the semantic-only condition. The remaining $30 \%$ of miscellaneous responses in each condition either were incomplete responses $(10 \%$ in the semantic plus morphophonological condition and $12 \%$ in the semanticonly condition) or had an erroneous substitution of an object noun. None of the latter responses met the criteria for either a complex verb error score or a simple-verb error score.

\section{Discussion}

As in Experiment 1, both the semantic-only and the semantic plus morphophonological conditions exhibited an asymmetry in contextual errors, with semantically more complex verbs replacing simple verbs more often than the reverse. However, unlike in Experiment 1, the asymmetry was statistically equal in both conditions, indicating that the addition of progressive aspect to the semantically more complex verb in the semantic plus morphophonological condition did not further increase its competitiveness. Furthermore, the numerically larger asymmetry in the semantic plus morphophonological condition includes both errors in which the complete progressive-marked form of the complex verb replaced the simple verb, and errors in which only the complex verb's stem replaced the simple verb's stem. When only the errors involving the movement of the complete forms of the complex and simple verbs are considered, the asymmetry in the semantic plus morphophonological condition is slightly less than that in the semantic-only condition (see Table 7).

There was no reliable correlation between the relative dominance of the simple verb's log frequency in the 32 pairs and the size of the asymmetry in complex verb errors associated with each pair in either the semantic plus morphophonological condition $(r=.09)$ or the semantic-only condition $(r=-.26, p=.16)$.

Approximately $20 \%$ of the responses in the semantic plus morphophonological condition exhibited an aspectmarking error. Most of these responses (84\%) resulted in the production of both the simple and the complex verbs without progressive aspect or both with progressive aspect, which most likely resulted from a general tendency for conjoints to be parallel in both their structure and their meaning. Although more aspect-marking errors in the semantic plus morphophonological condition involved the deletion of progressive aspect feature from the complex verb than to the addition of a progressive aspect to the simple verb, when the aspect-marking errors in both conditions are considered, the incidence of a deletion of progressive aspect is about the same as the incidence of an addition of progressive aspect.

\section{GENERAL DISCUSSION}

Both experiments demonstrated an asymmetry in perseveratory and anticipatory errors involving semantically related verbs that contrasted in their semantic complexity. Specifically, in Experiment 1, the verbs of antonym pairs that possessed an added negation feature replaced their semantically simpler and more frequent counterpart more often than the reverse. In Experiment 2, semantically heavy verbs or verbs with more specific meanings replaced more frequent light or general verbs more often than the reverse. In both experiments, the asymmetry in errors occurred regardless of whether there was a cor- 
responding contrast in the verbs' morphophonological complexity. Thus, the results provide evidence that when two verbs with overlapping semantic representations are to be encoded in the same utterance, the additional highly activated semantic features of the complex verb increase the competitiveness of its lemma in comparison with the simpler verb's lemma.

The results of Experiment 1 also suggest that the competitiveness at the lemma level is further increased when the contrast in the semantic complexity of verb antonyms is reflected in a corresponding contrast in their morphophonological complexity. In particular, the asymmetry in errors was significantly greater for verb antonyms that contrasted with respect to the absence versus presence of a prefix - such as zip-unzip - than for verb antonyms that have equally complex morphophonological forms, such as inflate-deflate. The characteristics of both the complex verb errors and the simple verb errors were consistent with a misordering involving the verbs' lemmas. Thus, one possible explanation for the greater incidence of complex verb errors in the semantic plus morphophonological condition is that the complex verb's lemma was more competitive due not only to top-down activation from an additional semantic feature, but also to bottom-up or feedback activation from an additional morpheme. In the semantic-only condition, the greater competitiveness of the complex verb's lemma would have been due only to top-down activation from an additional semantic feature, because the amount of feedback activation from the morphophonological level would have been the same for both the complex verb and simple verb. This feedback account is consistent with Dell and Reich's (1981) findings that the interacting words in spontaneously occurring exchanges, anticipations, and perseverations share more phonological features than would be expected by chance.

However, an alternative explanation for the difference in the size of the asymmetry in the two conditions is that the markedness of the verbs' morphophonological forms directly reflects the markedness - or contrast in complexity - of their semantic representations. In particular, whereas the contrast between the addition versus deletion of a prefix on the antonyms in the semantic plus morphophonological condition corresponds to a contrast in the addition versus deletion of a negation feature in their semantic representations, the presence of a prefix on both antonyms in the semantic-only condition may correspond to the presence of an opposing feature in both verbs' semantic representations. Thus, the reliable - albeit smaller - asymmetry in the errors that occurred in the semantic-only condition may be due to a stronger feature associated with the verbs that were classified as semantically more complex.

According to markedness theory, one consequence of the semantically unmarked or simpler word lacking a feature that explicitly signals an opposition with the marked counterpart is that it occurs in contexts in which the marked counterpart does not (see, e.g., Greenberg, 1966; Jakobson, 1957, 1984; Waugh, 1982). So, for example, whereas both dress and undress occur in the context of clothing, only the simpler, unmarked verb dress occurs in the context of food (cf. The chef dressed the salad vs. The chef undressed the salad or The chef dressed the turkey vs. The chef undressed the turkey). To determine whether the contextual distribution of the semantically simple verbs in the two conditions differ, an approximate measure of this distribution was obtained from the WordNet database (Miller et al., 1990) by counting the number of each verb's synsets, which are sets of synonyms corresponding to the different senses of a word. This measure provides some support for the difference in the size of the asymmetry in the two conditions being due to a difference in the antonyms' semantic markedness (complexity). In particular, in the semantic plus morphophonological condition, the average number of synsets listed for the simple verbs was 6.9 , and the average number of synsets listed for the complex verbs was 2.1 . In the semantic-only condition, the average number of synsets listed for the simple verbs was 3.3 , which was about equal to the average number of 2.8 synsets listed for the complex verbs.

Thus, it is unclear whether the larger asymmetry in the semantic plus morphophonological condition is due to feedback from the morphophonological level or a stronger markedness contrast at the semantic level. Nevertheless, the occurrence of an asymmetry in both conditions provides evidence for differential competition among the verbs' lemmas that is due to a contrast in their semantic representations.

Experiment 2 also demonstrated a reliable asymmetry favoring complex verb errors, but it was for semantically related verbs that contrasted with respect to the specificity of their meaning as a result of the complex verb possessing features for manner, patient affectedness, instrument, and so on. ${ }^{4}$ Furthermore, unlike in Experiment 1, there was no reliable increase in the asymmetry in the semantic plus morphophonological condition in which the complex verbs also possessed an additional diacritical feature for progressive aspect, which was morphophonologically realized by the addition of -ing and an auxiliary verb. However, among the many possible reasons for this null result, one possibility is that the marking of aspectual features occurs on the functional or phrasal categories of the plan for utterances as opposed to the semantic representations responsible for activating the lemmas that are to be assigned to slots within the plan (e.g., Garrett, 1975, 1988; Lapointe \& Dell, 1989). This assumption is motivated in part by stranding errors, such as I'm not in the read for mooding (Garrett, 1975), which reflect a tendency for stems of words to move to erroneous positions while leaving their inflections behind in the correct positions.

Overall, the asymmetry favoring complex verb errors that was observed in both experiments is consistent with a decompositional view of lexical semantic representations (see, e.g., Bierwisch \& Schreuder, 1992; Gordon \& Dell, 2002, 2003; Jackendoff, 1990; Miller \& Johnson-Laird, 1976; Pinker, 1989). One implication of this view is that lemmas that have a hypernym-hyponym relation will be asymmetrically activated because of the contrast in the number of their overlapping semantic features. However, the present study's results show that the effects of this asymmetrical activation on the process of selecting a lemma for assignment to the syntactic plan are observed when both lemmas are to be encoded within the same utterance. More specifically, when both lemmas di- 
rectly compete with each other, the greater competitiveness of the semantically marked hyponym, which is due to the additional activated semantic features, is manifested in a greater tendency for it to erroneously replace the hypernym rather than the reverse. Noncontextual word-substitution errors do not exhibit either a consistent frequency asymmetry or a consistent complexity (markedness) asymmetry, because if the highly activated semantic representation is underspecified (i.e., it is consistent with the hypernym), then frequency will resolve the competition in favor of the hypernym. However, when the highly activated semantic representation is fully specified (i.e., it is consistent with the hyponym), then the additional activated semantic features will resolve the competition in favor of the hyponym. In other words, this account is consistent with the general interaction between contextual constraints and frequency observed in production (e.g., Breedin et al., 1998; Gordon \& Dell, 2002, 2003; Griffin \& Bock, 1998; Stemberger, 1991, 2004), comprehension (e.g., MacDonald, Pearlmutter, \& Seidenberg, 1994; Tanenhaus \& Trueswell, 1995), and human performance in general (e.g., Reason, 1990, 1992).

\section{AUTHOR NOTE}

The research in this article constituted the first author's master's thesis. Portions of the research were presented at the 26th Annual Conference of the Cognitive Science Society, Chicago, IL. Correspondence concerning this article should be addressed to K. T. Eberhard, Department of Psychology, University of Notre Dame, Notre Dame, IN 46556 (e-mail: eberhard.1@nd.edu).

\section{REFERENCES}

BAARs, B J. (1992). A dozen competing-plans techniques for inducing predictable slips in speech and action. In B. J. Baars (Ed.), Experimental slips and human error (pp. 129-150). New York: Plenum.

BAARS, B. J., \& MACKAY, D. G. (1978). Experimentally eliciting phonetic and sentential speech errors: Methods, implications, and work in progress. Language in Society, 7, 105-109.

Batyen, R. H., Piepenbrock, R., \& Gulikers, L. (1995). The CELEX Lexical Database [CD-ROM]. Philadelphia: Linguistic Data Consortium.

Berndt, R. S., Haendiges, A. N., Mitchum, C. C., \& Sandson, J. (1997). Verb retrieval in aphasia: 2. Relationship to sentence processing. Brain \& Language, 56, 107-137.

Bierwisch, M., \& Schreuder, R. (1992). From concepts to lexical items. Cognition, 42, 23-60.

Bock, J. K. (1982). Toward a cognitive psychology of syntax: Information processing contributions to sentence formulation. Psychological Review, 89, 1-47.

Bock, J. K. (1986). Meaning, sound, and syntax: Lexical priming in sentence production. Journal of Experimental Psychology: Learning, Memory, \& Cognition, 12, 575-586.

Bock, K. (1995). Sentence production: From mind to mouth. In J. L. Miller \& P. D. Eimas (Eds.), Handbook of perception and cognition: Vol. 11. Speech, language, and communication. (pp. 181-216). Orlando, FL: Academic Press.

Bock, K., \& Levelt, W. (1994). Language production: Grammatical encoding. In M. A. Gernsbacher (Ed.), Handbook of psycholinguistics (pp. 945-984). San Diego: Academic Press.

Breedin, S. D., Boronat, C. B., Saffran, E. M., \& Shipley, J. E. (1999). The role of semantic complexity in verb retrieval: Part 2. Brain \& Language, 69, 264-267.

Breedin, S. D., Saffran, E. M., \& Schwartz, M. F. (1998). Semantic factors in verb retrieval: An effect of complexity. Brain \& Language, 63, 1-31.

ButTerworth, B. (1989). Lexical access in speech production. In W. D. Marslen-Wilson (Ed.), Lexical representation and process (pp. 108135). Cambridge, MA: MIT Press.
Clark, H. H., \& StAFFord, R. A. (1969). Memory for semantic features in the verb. Journal of Experimental Psychology, 80, 326-334.

Cohen, J. D., MacWhinney, B., Flatt, M., \& Provost, J. (1993). PsyScope: An interactive graphic system for designing and controlling experiments in the psychology laboratory using Macintosh computers. Behavioral Research Methods, Instruments, \& Computers, 25, 257-271.

Comrie, B. (1998). Aspect. Cambridge: Cambridge University Press.

Costa, A., Caramazza, A., \& Sebastián-Gallés, N. (2000). The cognate facilitation effect: Implications for models of lexical access. Journal of Experimental Psychology: Learning, Memory, \& Cognition, 26, 1283-1296.

Cutting, J. C., \& Ferreira, V. S. (1999). Semantic and phonological information flow in the production lexicon. Journal of Experimental Psychology: Learning, Memory, \& Cognition, 25, 318-344.

Dell, G. S. (1985). Positive feedback in hierarchical connectionist models: Applications to language production. Cognitive Science, 9, 2-23.

DELL, G. S. (1986). A spreading-activation theory of retrieval in sentence production. Psychological Review, 93, 283-321.

DELL, G. S. (1990). Effects of frequency and vocabulary type on phonological speech errors. Language \& Cognitive Processes, 5, 313-349.

Dell, G. S., Burger, L. K., \& Svec, W. R. (1997). Language production and serial order: A functional analysis and a model. Psychological Review, 104, 123-147.

Dell, G. S., \& O'Seaghdha, P. G. (1992). Stages of lexical access in language production. Cognition, 42, 287-314.

Dell, G. S., \& ReICH, P. A. (1981). Stages in sentence production: An analysis of speech error data. Journal of Verbal Learning \& Verbal Behavior, 20, 611-629.

Dell, G. S., Schwartz, M. F., Martin, N., Saffran, E. M., \& GaGNON, D. A. (1997). Lexical access in aphasic and nonaphasic speakers. Psychological Review, 104, 810-838.

del Viso, S., IgOA, J. M., \& García-Albea, J. E. (1991). On the anatomy of phonological encoding: Evidence from slips of the tongue in Spanish. Journal of Psycholinguistic Research, 20, 161-185.

Ferreira, F. S., \& Humphreys, K. R. (2001). Syntactic influences on lexical and morphological processing in language production. Journal of Memory \& Language, 44, 52-80.

Fodor, J. A., Garrett, M. F., Walker, E. C T., \& Parkes, C. H. (1980). Against definitions. Cognition, 8, 263-267.

Fromkin, V. A. (Ed.) (1973). Speech errors as linguistic evidence. The Hague: Mouton.

Garrett, M. F. (1975). The analysis of sentence production. In G. H. Bower (Ed.), The psychology of learning and motivation (Vol. 9). New York: Academic Press.

GARRETT, M. F. (1980). Levels of processing in sentence production. In B. Butterworth (Ed.), Language production (Vol. 1, pp. 177-220). London: Academic Press.

Garrett, M. F. (1982). Production of speech: Observations from normal and pathological language use. In A. W. Ellis (Ed.), Normality and pathology in cognitive functions (pp. 19-76). New York: Academic Press.

Garrett, M. F. (1988). Processes in language production. In F. J. Newmeyer (Ed.), Linguistics: The Cambridge survey, III. Language: Psychological and biological aspects (pp. 69-96). Cambridge: Cambridge University Press.

GARRETT, M. (1992). Lexical retrieval processes: Semantic field effects. In E. F. Kittay \& A. Lehrer (Eds.), Frames, fields, and contrasts: New essays in semantic and lexical organization (pp. 377-395). Hillsdale, NJ: Erlbaum.

GARRETT, M. (2001). Now you see it, now you don't: Frequency effects in language production. In E. Dupoux (Ed.), Language, brain, and cognitive development: Essays in honor of Jacques Mehler (pp. 227240). Cambridge, MA: MIT Press.

Gordon, J. [K.], \& Dell, G. [S.] (2002). Learning to divide the labor between syntax and semantics: A connectionist account of deficits in light and heavy verb production. Brain \& Cognition, 48, 376-381.

Gordon, J. K., \& Dell, G. S. (2003). Learning to divide the labor: An account of deficits in light and heavy verb production. Cognitive Science, 27, 1-40.

Greenberg, J. H. (1966). Language universals. The Hague: Mouton.

Griffin, A. M., \& Bock, K. (1998). Constraint, word frequency, and the relationship between lexical processing levels in spoken word production. Journal of Memory \& Language, 38, 313-338. 
Harley, T. A. (1993). Phonological activation of semantic competitors during lexical access in speech production. Language \& Cognitive Processes, 8, 291-309.

Harley, T. A., \& MacAndrew, S. B. G. (2001). Constraints upon word substitution speech errors. Journal of Psycholinguistic Research, 30, 395-418.

Hartsuiker, R. J., Corley, M., \& Martensen, H. (2005). The lexical bias effect is modulated by context, but the standard monitoring account doesn't fly: Related reply to Baars et al. (1975). Journal of Memory \& Language, 52, 58-70.

Hоторғ, W. H. N. (1980). Semantic similarity as a factor in whole-word slips of the tongue. In V. A. Fromkin (Ed.), Errors in linguistic performance (pp. 97-109). San Diego: Academic Press.

JACKendoff, R. (1990). Semantic structures. Cambridge, MA: MIT Press.

JACKENDOFF, R. (1991). Parts and boundaries. Cognition, 41, 9-45.

JAKOBSON, R. (1957). Shifters, verbal categories, and the Russian verb (Russian Language Project Report). Cambridge, MA.: Harvard University, Department of Slavic Languages and Literatures.

JAKOBSON, R. (1984). Russian and Slavic grammar studies. Berlin: Mouton.

Janssen, D. P., Roelofs, A., \& Levelt, W. J. M. (2002). Inflectional frames in language production. Language \& Cognitive Processes, 17, 209-236.

Janssen, D. P., Roelofs, A., \& Levelt, W. J. M. (2004). Stem complexity and inflectional encoding in language production. Journal of Psycholinguistic Research, 33, 365-381.

Jescheniak, J. D., \& LeVelt, W. J. M. (1994). Word frequency effects in speech production: Retrieval of syntactic information and phonological form. Journal of Experimental Psychology: Learning, Memory, \& Cognition, 20, 824-843.

JescheniaK, J. D., \& SCHRIEFERs, H. (1998). Discrete serial versus cascaded processing in lexical access in speech production: Further evidence from the coactivation of near-synonyms. Journal of Experimental Psychology: Learning, Memory, \& Cognition, 24, 1256-1274.

JESPERSON, O. (1965). A modern English grammar on historical principles. London: Allen \& Unwin.

Kohn, S. E., Lorch, M. P., \& Pearson, D. M. (1989). Verb finding in aphasia. Cortex, 25, 57-69.

Lapointe, S. G., \& Dell, G. S. (1989). A synthesis of some recent work in sentence production. In G. N. Carlson \& M. K. Tanenhaus (Eds.), Linguistic structure in language processing (pp. 107-156). Boston Kluwer.

Levelt, W. J. M. (1989). Speaking: From intention to articulation Cambridge, MA: MIT Press.

Levelt, W. J. M., Roelofs, A., \& Meyer, A. S. (1999). A theory of lexical access in speech production. Behavioral \& Brain Sciences, 22, 1-75.

MacDonald, M. C., Pearlmutter, N. J., \& Seidenberg, M. S. (1994). Lexical nature of syntactic ambiguity resolution. Psychological Review, 101, 676-703.

Marshall, J., Pring, T., Chiat, S., \& Robson, J. (2001). When ottoman is easier than chair: An inverse frequency effect in jargon aphasia. Cortex, 37, 33-53.

Martin, N., Weisberg, R. W., \& Saffran, E. M. (1989). Variables influencing the occurrence of naming errors: Implications for models of lexical retrieval. Journal of Memory \& Language, 28, 462-485.

Melinger, A. (2003). Morphological structure in the lexical representation of prefixed words: Evidence from speech errors. Language \& Cognitive Processes, 18, 335-362.

Miller, G. A., Beckwith, R., Fellbaum, C., Gross, D., \& Miller, K. (1990). Introduction to WordNet: An online lexical database. International Journal of Lexicography, 3, 235-312.

Miller, G. A., \& Johnson-LaIRD, P. N. (1976). Language and perception. Cambridge, MA: Harvard University Press.

OldField, R. C., \& WingField, A. (1965). Response latencies in naming objects. Quarterly Journal of Experimental Psychology, 17, 273281.

Peterson, R. R., \& Savoy, S. (1998). Lexical selection and phonological encoding during language production: Evidence for cascaded processing. Journal of Experimental Psychology: Learning, Memory, \& Cognition, 24, 539-557.

Pillon, A. (1998). Morpheme units in speech production: Evidence from laboratory-induced verbal slips. Language \& Cognitive Processes, 13, 465-498.

PINKER, S. (1989). Learnability and cognition: The acquisition of argument structure. Cambridge, MA: MIT Press.

PINKER, S. (1999). Words and rules: The ingredients of language. New York: Basic Books.

Quirk, R., Greenbaum, S., Leech, G., \& Svartvik, J. (1985). A comprehensive grammar of the English language. London: Longman.

RAPP, B., \& GolDRICK, M. (2000). Discreteness and interactivity in spoken word production. Psychological Review, 107, 460-499.

RAPP, B., \& GoldRICK, M. (2004). Feedback by any other name is still interactivity: A reply to Roelofs (2004). Psychological Review, 111, 573-578.

Reason, J. [T.] (1990). Human error. New York: Cambridge University Press.

Reason, J. T. (1992). Cognitive underspecification: Its variety and consequences. In B. J. Baars (Ed.), Experimental slips and human error: Exploring the architecture of volition, cognition and language (pp. 71-91). New York: Plenum.

RoELOFs, A. (1992). A spreading-activation theory of lemma retrieval in speaking. Cognition, 42, 107-142.

Roelofs, A. (1993). Testing a non-decompositional theory of lemma retrieval in speaking: Retrieval of verbs. Cognition, 47, 59-87.

RoElOFs, A. (1996). Serial order in planning the production of successive morphemes of a word. Journal of Memory \& Language, 35, 854 876.

Roelofs, A. (1997). A case for non-decomposition in conceptually driven word retrieval. Journal of Psycholinguistic Research, $\mathbf{2 6}$, 33-67.

Roelofs, A. (2004). Comprehension-based versus production-internal feedback in planning spoken words: A rejoinder to Rapp and Goldrick (2004). Psychological Review, 111, 579-580.

RoElofs, A., \& BAAYEN, H. (2002). Morphology by itself in planning the production of spoken words. Psychonomic Bulletin \& Review, 9 , 132-138.

Rumelhart, D. E., \& McClelland, J. L. (1986). Parallel distributed processing: Exploring the microstructures of cognition (Vol. 1). Cambridge: MIT Press.

Schade, U., \& BERG, T. (1992). The role of inhibition in a spreading activation model of language production: II. Simulational perspective. Journal of Psycholinguistic Research, 21, 435-462.

Starreveld, P. A., \& LA HeiJ, W. L. (1999). Word substitution errors in a speeded picture-word task. American Journal of Psychology, 112 521-553.

Stemberger, J. P. (1985). An interactive activation model of language production. In A. Ellis (Ed.), Progress in the psychology of language (Vol. 1, pp. 143-186). London: Erlbaum.

Stemberger, J. P. (1990). Wordshape errors in language production. Cognition, 35, 123-157.

Stemberger, J. P. (1991). Apparent anti-frequency effects in language production: The addition bias and phonological underspecification. Journal of Memory \& Language, 30, 161-185.

Stemberger, J. P. (1992). The reliability and replication of naturalistic speech error data: A comparison with experimentally induced errors. In B. J. Baars (Ed.), Experimental slips and human error (pp. $195-$ 216). New York: Plenum Press.

Stemberger, J. P. (2004). Neighborhood effects on error rates in speech production. Brain \& Language, 90(1-3), 413-422.

Stemberger, J. P., \& MacWhinney, B. (1986). Frequency and the lexical storage of regularly inflected forms. Memory \& Cognition, 14, 17-26.

Stemberger, J. P., \& Treiman, R. (1986). The internal structure of word-initial consonant clusters. Journal of Memory \& Language, 25 , 163-180.

Tanenhaus, M. K., \& Trueswell, J. C. (1995). Sentence comprehension. In J. L. Miller \& P. D. Eimas (Eds.), Handbook of perception and cognition: Vol. 11. Speech, language, and communication (pp. $217-$ 262). Orlando, FL: Academic Press.

WaUgh, L. R. (1982). Marked and unmarked: A choice between unequals in semiotic structure. Semiotica, 38, 299-318.

WingFIELD, A. (1967). Perceptual and response hierarchies in object identification. Acta Psychologica, 26, 216-226. 
WiNGFIELD, A. (1968). Effects of frequency on identification and naming of objects. American Journal of Psychology, 81, 226-234.

\section{NOTES}

1. The effect of the number of processing units that spread positive or excitatory activation to a receiving unit typically occurs in the calculation of the net input to a unit $i$, which is commonly computed by the formula

$$
\text { net }_{i}=\sum_{j} w_{i j} a_{j} \text {, }
$$

where $w_{i j}$ is the weights of the connections between sending units $j$ and the receiving unit $i$, and $a_{j}$ is the activation level of the sending units $j$ (see, e.g., Rumelhart \& McClelland, 1986).

2. Here and throughout the article, speech errors are illustrated with the intended utterance given on the left side of an arrow $(\rightarrow)$ and the actually produced erroneous utterance given in italics on the right side.

3. One verb pair, maximize-minimize, consisted of different base morphemes bound to the same suffix.

4. The average number of synsets (senses) listed in WordNet for the simple verbs is 20.3 , whereas the average number of synsets listed for the complex verbs is 4.4

\section{APPENDIX A \\ Critical Sentences Used in Experiment 1}

There were four versions of each sentence, created by crossing of the order of the simple and complex verbs with the order of the complement phrases that followed them. The sentences below are the versions in which the simpler verb occurs first. The numbers in parentheses are the log of the frequencies of the simple verb's lemma and the complex verb's lemma, respectively.

\section{Semantic plus morphophonological condition}

1. They agree with the law and disagree with the bill. $(3.53,2.41)$

2. It appears at home and disappears at work. $(3.72,3.09)$

3 . She approves of the play and disapproves of the project. $(2.90,2.20)$

4. We arm the soldiers and disarm the rebels. $(2.00,2.00)$

5 . He assembles the axle and disassembles the engine. $(2.63,0.50)$

6. He bends the branch and unbends the wire. $(3.07,0.78)$

7. He chains the bike and unchains the dog. $(2.03,0.50)$

8 . It clogs the sink and unclogs the tub. $(1.86,0.00)$

9. He continues the subscription and discontinues the lease. $(2.03,0.50)$

10. She covers the rice and uncovers the sauce. $(3.51,2.09)$

11. She dresses the doll and undresses the bear. $(3.17,2.17)$

12. He likes the hills and dislikes the woods. $(3.77,2.62)$

13. They lock the gate and unlock the door. $(3.04,2.42)$

14. They obey the king and disobey the queen. $(2.67,1.76)$

15. He packs the car and unpacks the bag. $(2.84,1.92)$

16. She pleases the council and displeases the client. $(2.51,1.88)$

17. She respects the boss and disrespects the peer. $(2.10,0.30)$

18. He seals the file and unseals the form. $(2.51,0.50)$

19. She ties the knot and unties the shoe. $(3.04,0.50)$

20. She zips the coat and unzips the purse. $(1.64,1.59)$

\section{Semantic only}

1. She accelerates the thruster and decelerates the airplane. $(2.43,1.00)$

2. He assents to the plan and dissents to the path. $(1.20,1.32)$

3 . She associates with her parent and dissociates with her sibling. $(2.97,1.49)$

4. We attach the trim and detach the thread. $(2.94,2.00)$

5 . We conjoin the poems and disjoin the stanzas. $(0.85,0.70)$

6 . They consecrate the hall and desecrate the home. $(1.65,1.36)$

7. They converge at the hotel and diverge at the park. $(2.02,1.57)$

8 . They enable the program and disable the virus. $(2.98,1.30)$

9. He encodes the message and decodes the signal. $(1.20,1.54)$

10. He encourages his son and discourages his wife. $(1.66,0.95)$

11. They explode the garage and implode the building. $(2.60,0.50)$

12. We export the glass and import the steel. $(2.26,2.58)$

13. It includes the pamphlets and excludes the pieces. $(3.36,2.62)$

14. She increases the price and decreases the stock. $(3.62,2.41)$

15. We inflate the mattress and deflate the balloon. $(1.77,1.59)$

16. She inhales the smoke and exhales the air. $(1.97,1.66)$

17. We invest the money and divest the interest. $(2.72,0.50)$

18. They maximize the profits and minimize the returns. $(2.14,2.23)$

19. They progress with the cure and regress with the cause. $(2.47,1.38)$

20. She promotes the agent and demotes the driver. $(2.77,1.36)$ 


\section{APPENDIX B \\ Critical Sentences Used in Experiment 2}

In the critical sentences representing the semantic plus morphophonological condition in Experiment 2, the complex verb was morphophonologically marked with present-progressive tense. The sentences representing the semantic-only condition were the same, except that both the simple and the complex verbs appeared in their simple present-tense form. There were four versions of each sentence in each condition. The versions represented a crossing of the order of the verbs with the order of the complement phrases that followed them. The numbers in parentheses are the log frequencies of the simple verb's lemma and the complex verb's lemma, respectively.

1. He asks for help and is begging for respect. $(4.17 ; 2.74)$

2. He stands in the corner and is lurking in the hallway. $(3.92 ; 2.19)$

3. She cuts the onions and is chopping the peppers. $(3.53 ; 2.54)$

4. We cause the fortune and are jinxing the outcome. $(3.49 ; 0.70)$

5. They break the crystal and are smashing the china. $(3.61 ; 2.64)$

6 . They get the van and are seizing the car. $(4.63 ; 2.76)$

7. He has the sheath and is gripping the sword. $(5.38 ; 2.42)$

8 . They know the platform and are backing the party. $(4.58 ; 2.70)$

9. He puts the disks on the shelf and is stacking the clips on the floor. $(4.16 ; 2.30)$

10. She gives the money and is lending the advice. $(4.36 ; 2.69)$

11. She wants the chocolate and is craving the yogurt. $(4.30 ; 1.95)$

12. We say the complaint and are voicing the comment. $(4.88 ; 1.81)$

13. They set the wig and are posing the hair. $(3.75 ; 2.70)$

14. He tells the patient and is warning the doctor. $(4.28 ; 2.95)$

15. They change the letters and are shrinking the margins. $(3.92 ; 2.56)$

16. We do the content and are fixing the layout. $(4.91 ; 2.86)$

17. She lives in the desert and is dwelling in the shelter. $(3.97 ; 2.21)$

18. She stays in the room and is resting in the house. $(3.65 ; 2.97)$

19. They move the desk and are sliding the box. $(3.88 ; 2.80)$

20. She goes to the zoo and is jogging to the park. $(4.71 ; 1.91)$

21 . We run with the baton and are springing with the trophy. $(3.90 ; 2.78)$

22. She eats the jello and is slurping the pudding. $(3.71 ; 1.20)$

23. He comes to the lake and is strolling on the shore. $(4.55 ; 2.37)$

24 . He sees the answers and is viewing the exam. $(4.57 ; 2.73)$

25 . We make the bowl and are sculpting the vase. $(4.62 ; 1.32)$

26. He takes the cow and is stealing the horse. $(4.54 ; 2.97)$

27 . They touch the orange and are poking the apple. $(3.29 ; 2.40)$

28 . We bring the bag and are fetching the coat. $(3.96 ; 2.58)$

29 . We keep the papers and are filing the records. $(4.07 ; 2.57)$

30 . She feels the carpet and is stroking the curtain. $(4.19 ; 2.53)$

31 . They cover the jewel and are encasing the diamond. $(3.51 ; 1.81)$

32 . We become a group and are replacing the team. $(4.17 ; 3.13)$ 
APPENDIX C

Example Transcriptions of Responses in Each Error Score Category in Experiments 1 and 2

\begin{tabular}{|c|c|c|}
\hline Error Category & $\begin{array}{c}\text { Semantic Plus } \\
\text { Morphophonological }\end{array}$ & Semantic Only \\
\hline
\end{tabular}

\section{Experiment 1}

Complex verb She uncovers the sauce and covers the rice.

She uncovers the sauce and uncovers the rice.

Simple verb She unties the shoe and ties the knot.

She ties the ... she ties the shoes and ties the knot.

Exchange It unclogs the tub and clogs the sink. It clogs the tub and unclogs the sink.

Miscellaneous She displeases the client and pleases the council.

She displeases the council and pleases the client.

She undresses the doll and dresses the bear.

She undoes the bear and does the doll.

Experiment 2

Complex verb

Simple verb

Exchange

Aspect marking

\section{We are voicin
complaint.}

We are voicing the com ... comment and voicing the complaint.

She is lending the advice and gives the money.

She is lending the advice and lends the money.

She is stroking the curtain and feels the carpet.

She feels the ... is stroking the curtain and feels the carpet.

He asks for respect and is begging for help. He asks for respect and is asking for help.

He is warning the patient and tells the doctor.

He tells the patient and is warning the doctor.

They touch the orange and are poking the apple.

They touch the orange and poke the apple.

Miscellaneous

We say the comment and are voicing the complaint.

We say the compliment and are voicing the complaint.
They desecrate the hall and consecrate the home.

They desecrate the hall and desecrate the home.

They desecrate the home and consecrate the hall.

They con ... desecrate the home and consecrate the hall.

We export the steel and import the glass. We import the steel and export the glass.

They progress with the cause and regress with the cure.

They progress with the treatment and regress with the cure

It excludes the pieces and includes the pamphlets.

It includes the pieces and doesn't include the parts.

They touch the apple and poke the orange.

They poke ... touch the apple and poke the orange.

He asks for respect and begs for help.

He asks for respect and ... asks for help.

We bring the coat and fetch the bag.

We fetch the coat and bring the bag.

He lurks in the corner and stands in the hallway.

He lurks in the corner and is standing in the hallway.

She feels the curtain and strokes the carpet.

She feels the carpet and strokes a rug.

Note-Ellipses indicate pauses in the response. For each example, the italicized sentence shows the form of a correct reversal response.

(Manuscript received August 28, 2006;

revision accepted for publication October 19,2006.) 